\title{
Autosomal dominant inheritance of abnormalities of the hands and feet with short palpebral fissures, variable microcephaly with learning disability, and oesophageal/duodenal atresia
}

\author{
Han G Brunner, Robin M Winter
}

\begin{abstract}
We report two families with an autosomal dominant syndrome of abnormalities of the hands and feet, short palpebral fissures, and variable microcephaly with learning disability. Between a third and a quarter of cases are born with oesophageal atresia, duodenal atresia, or both. Individual patients have hypoplastic thumbs or congenital heart disease. The phenotype of the syndrome reported here is similar to that observed in 13q22-qter deletion patients. However, chromosome analysis has not detected any structural abnormality in our patients.
\end{abstract}

Oesophageal atresia and tracheo-oesophageal fistula occur in approximately 1 in 3000 births. ${ }^{12}$ Approximately half of the cases have additional malformations, mostly cardiac malformations, other gastrointestinal atresias, renal abnormalities, or radial ray defects. In some $6 \%$ of patients with oesophageal atresia and associated anomalies, an abnormal karyotype can be detected. Recurrence of oesophageal atresia is rare, with empirical risk estimates of 0.43 to $1.7 \%$ in sibs $^{2-4}$ and $3.6 \%$ in children. ${ }^{5}$ In a review of published reports on familial cases of oesophageal atresia, van Staey et $a l^{4}$ concluded that the data were most compatible with polygenic inheritance. Similarly, large series of cases with oesophageal atresia have shown little evidence for monogenic inheritance. ${ }^{2} 36$

We report on two families with an autosomal dominant syndrome of short palpebral fissures,

Department of Human Genetics, University Hospital Nijmegen, PO Box 9101, 6500 HB Nijmegen, The Netherlands.

H G Brunner

The Kennedy Galton Centre, Clinical Research Centre, Northwick Park Hospital, Harrow, Middlesex HA1 3UJ. R M Winter

Correspondence to Dr Brunner.

Received for publication 18 June 1990.

Revised version accepted for publication 2 November 1990. microcephaly, mild mental retardation, fifth finger clinodactyly, and syndactyly of the toes. Several affected subjects have shown congenital atresias of the gastrointestinal tract, especially oesophageal atresia and duodenal atresia. Two other families reported may have had the same syndrome.

\section{Case reports}

CASE 1 (III.8, FAMILY 1)

This boy was the first child born to non-consanguineous Dutch parents. The pregnancy was complicated by polyhydramnios. Delivery occurred spontaneously at 38 weeks' gestation. Birth weight was $2840 \mathrm{~g}$. Examination showed upward slanting, short palpebral fissures, marked clinodactyly of the fifth fingers, bilateral syndactyly of the fourth and fifth toes, and a large gap between the first and second toes. An oesophageal atresia with tracheo-oesophageal fistula was repaired on the second day of life. Laparotomy showed duodenal obstruction by an annular pancreas. A duodenoduodenostomy was performed. The child died on the fourth day of life. At necropsy, a complex cardiac malformation consisting of tricuspid atresia, VSD, and interrupted aortic arch was found. Chromosome studies showed a normal karyotype, $46, \mathrm{XY}$.

\section{CASE 2 (III.9, FAMILY 1)}

In her second pregnancy, the mother of case 1 again experienced polyhydramnios, confirmed by ultrasound from the 24th week onwards. Delivery occurred at 38 weeks. Birth weight was $3500 \mathrm{~g}$. On the first day of life, an oesophageal atresia with tracheo-oesophageal fistula and duodenal atresia (in combination with annular pancreas) were repaired. Similar phenotypic features to his brother's were noted (figs 1 to 3 ) with clinobrachydactyly of both little fingers and syndactyly of toes $2 / 3$ and $4 / 5$ bilaterally. In addition he had camptodactyly of the middle finger of the left hand. At the age of 12 months he is doing well. 


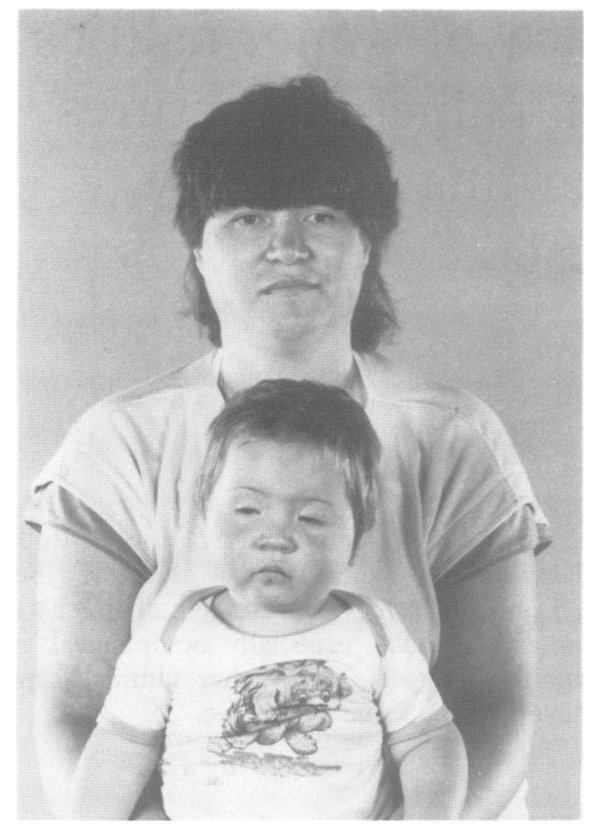

Figure 1 Cases 2 and $3(I I I \cdot 9$ and II $\cdot 7$, family 1$)$. Note short palpebral fissures.

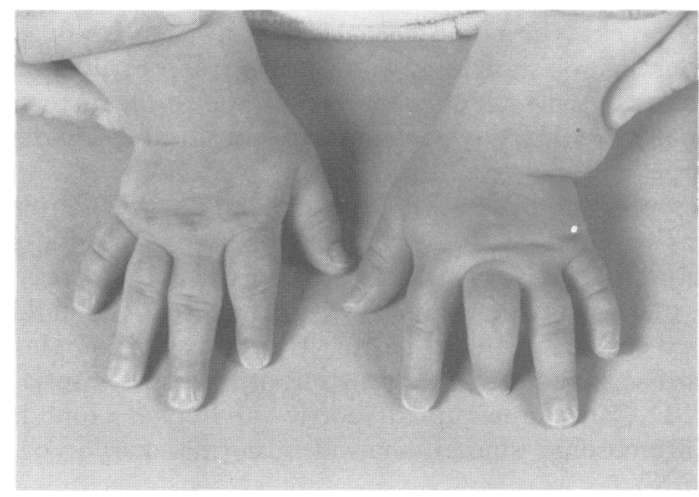

Figure 2 Hands of III.9 (family 1). Note flexion deformity of the left middle finger.

Length and weight are appropriate for his age. The OFC is $46 \mathrm{~cm}$ (10th centile). The palpebral fissures are short. ICD is $33 \mathrm{~mm}, O C D$ is $78 \mathrm{~mm}$. Ultrasound examination of the heart and kidneys showed no abnormalities. A G banded karyotype was normal, $46, X Y$.

CASE 3 (II.7, FAMILY 1)

This is the mother of subjects III $\cdot 8$ and III $\cdot 9$. She has a similar phenotype with brachymesophalangy of the

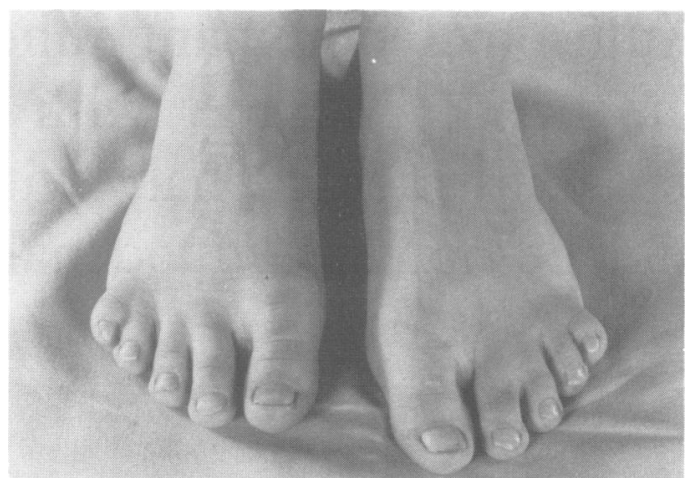

Figure 3 Feet of III.9 (family 1). Note bilateral syndactyly of toes $4 / 5$ and mild syndactyly of toes $2 / 3$.

index and little fingers bilaterally (fig 4). Both feet show $4 / 5$ syndactyly. The OFC is $53 \mathrm{~cm}$ (10th centile). Her palpebral fissures are short. She has attended a special school because of learning problems. High resolution chromosome analysis with special attention to chromosome 13 was normal.

Eight other family members have the same abnormalities of the hands and feet. Three have had operations in the neonatal period for oesophageal or duodenal atresia or both (figs 5 to 8 , table).

\section{CASE 4 (II.2, FAMILY 2)}

This was the second child born to non-consanguineous Indian parents. Delivery occurred spontaneously at 37 weeks. At birth, weight was $1990 \mathrm{~g}$, length was 39 $\mathrm{cm}$, and OFC was $28 \mathrm{~cm}$ (all $<3 \mathrm{rd}$ centile). She has a peculiar face with short palpebral fissures (fig 9). On examination, hypoplastic thumbs (fig 10), clinodactyly of the fifth fingers with a single flexion crease, and a large gap between the first and second toes were found. At 4 days of age she was admitted to the

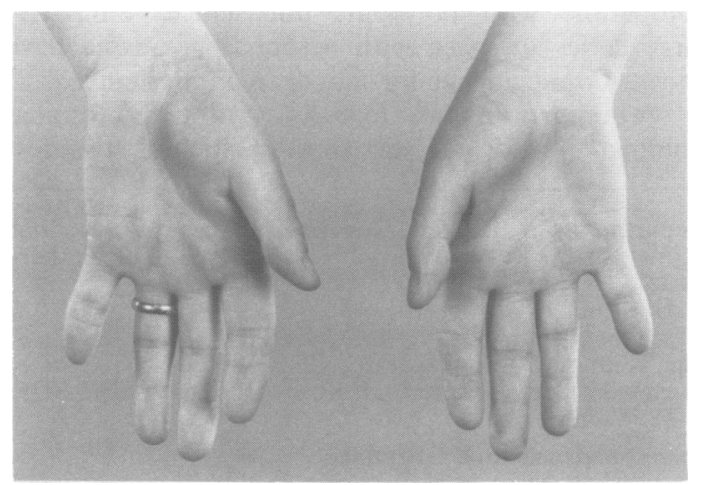

Figure 4 Hands of II $\cdot 7$ (family 1$)$. Note clinodactyly of second and fifth fingers. 


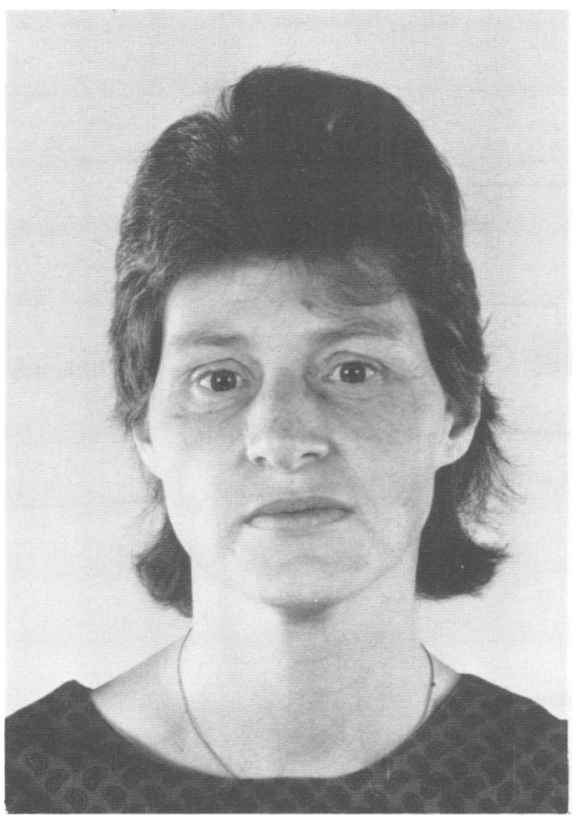

Figure 5 Sister of case $3(I I \cdot 3$, family 1$)$. Note microcephaly $(O F C=50.8 \mathrm{~cm})$ with short palpebral fissures $(I C D=28 \mathrm{~mm}$, $O C D=78 \mathrm{~mm}$ )

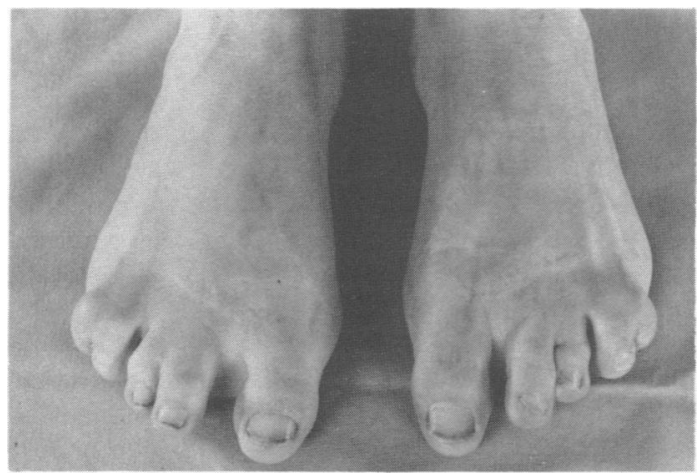

Figure 6 Feet of $I I \cdot 3$. Note bilateral syndactyly of toes $2 / 3$ and $4 / 5$.

surgical department because of persistent, not bile stained vomiting and a double bubble appearance on abdominal radiographs. Laparotomy at 4 days of age showed a duodenal obstruction owing to a wind sock type of membrane at the junction of the first and second parts of the duodenum. A duodenoduodenostomy was performed. The child recovered uneventfully. At 2 years of age she shows apparently normal development. On examination, the mother and brother of case 4 were found to have the same syndrome (figs 11 to 13 , table).

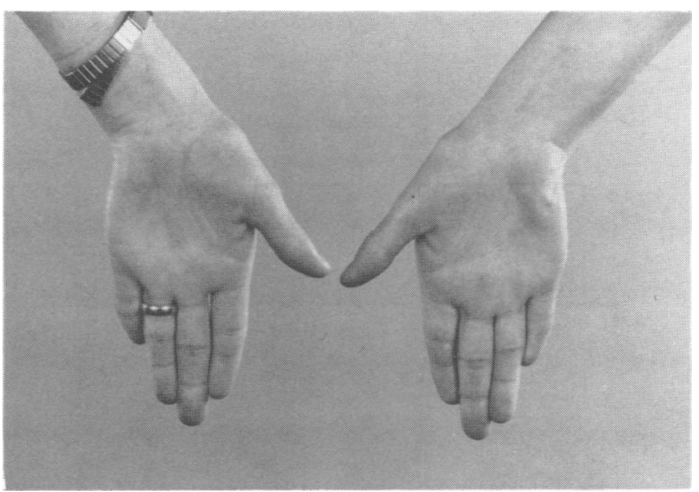

Figure 7 Hands of II $\cdot 3$. Note clinodactyly of fifth fingers.

\section{Family study}

Eleven subjects in family 1 and three subjects in family 2 are known to be affected. Two subjects in family 1 were unavailable for examination. II $\cdot 2$ died at the age of 15 months. Information about this girl was collected from her medical records and from her mother. II 6 could not be personally examined because she is living abroad. Information about this woman was obtained from the family and by examination of photographs.

Details of the two families are given below and are summarised in the table, together with data from two reports by Feingold $^{7}$ that describe the same syndrome.

\section{HAND AND FOOT ABNORMALITIES}

These are remarkably constant and occur with full penetrance. All affected subjects have brachymesophalangy of the fifth finger bilaterally. Marked syndactyly of the fourth and fifth toes was found in $12 / 13$ cases. Syndactyly of the second and third toes was usually less prominent and occurred in about $70 \%$ (8/11).

The proband in family $2(\mathrm{II} \cdot 2)$ has very small thumbs, but in all other persons thumb hypoplasia has been either mild or absent. Two subjects have clinodactyly of the index finger. In family 1 , subject III.9 has camptodactyly of the middle finger which has improved substantially over time. One person in family 1 and two in family 2 have a wide interdigital space between toes 1 and 2 .

\section{CRANIOFACIAL}

Affected subjects have short palpebral fissures with normal ICD and decreased OCD. In family 1 , affected persons tend to have lower OFCs than their unaffected sibs. However, only half of those for whom 


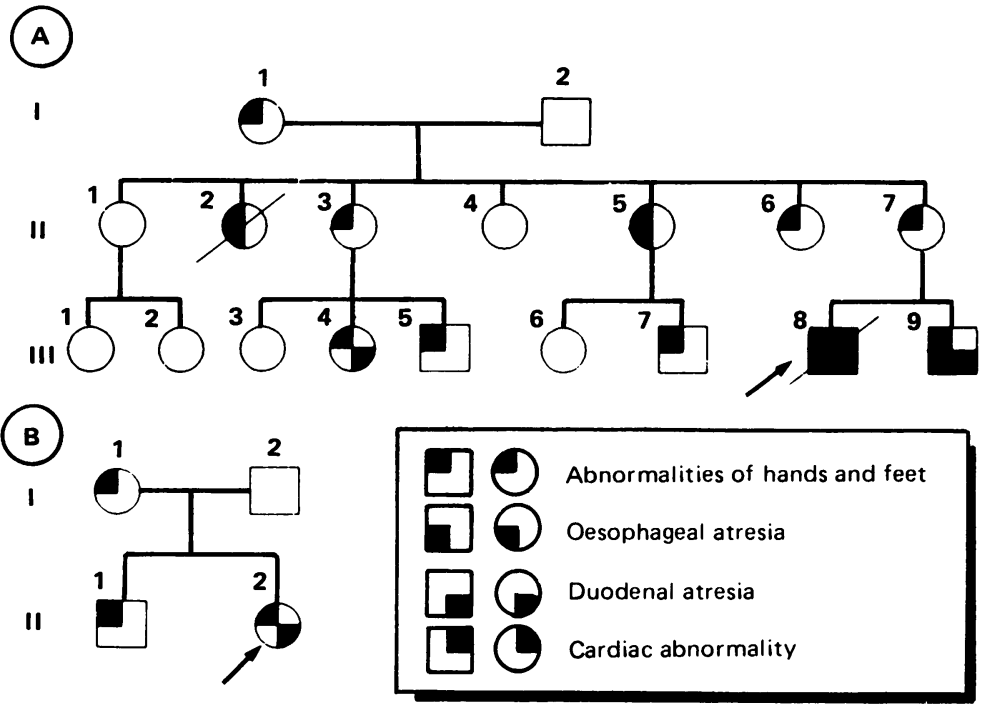

Figure 8 Pedigrees. Probands are indicated by an arrow.

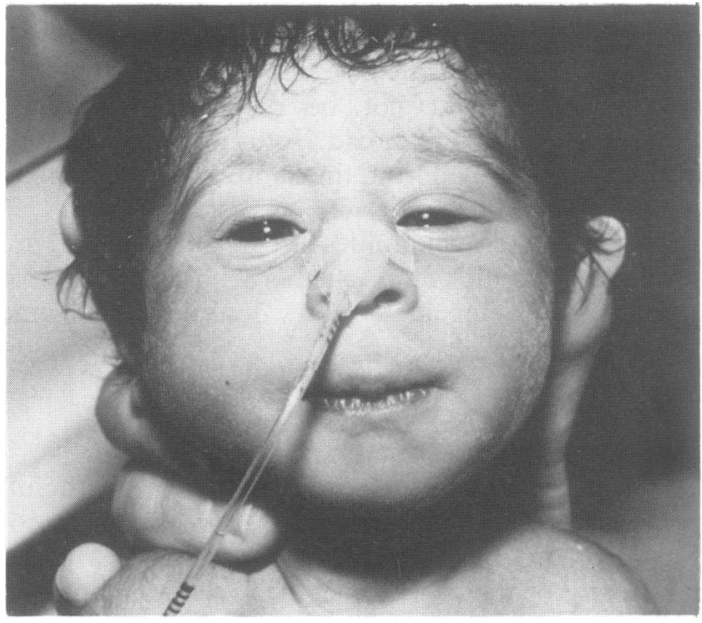

Figure 9 Case $4(I I \cdot 2$, family 2). Note short palpebral fissures and nasopharyngeal tube.

measurements are available (4/8) have an OFC below the 3rd centile. One subject has an OFC on the 25th centile. In family 2 , all three affected subjects are microcephalic.

\section{INTELLIGENCE}

Although none of the affected persons in family 1 is considered mentally retarded, five out of seven have attended special schools for children with learning disabilities. In contrast, all nine unaffected family members show normal cognitive development. In

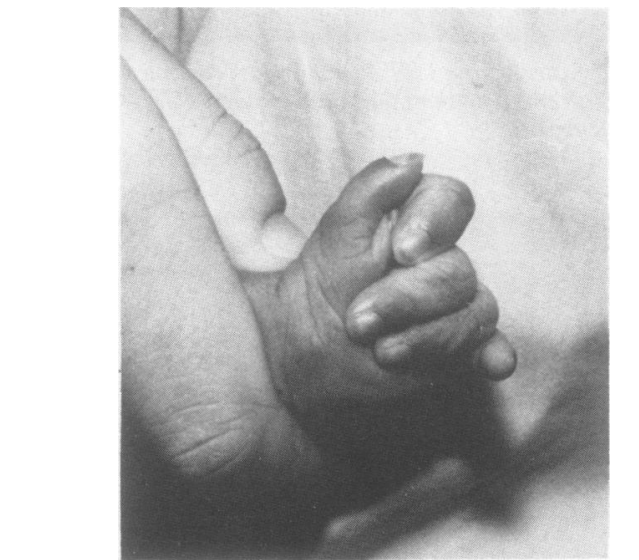

Figure 10 Left hand of $I I \cdot 2$ (family 2). Note hypoplastic thumb.

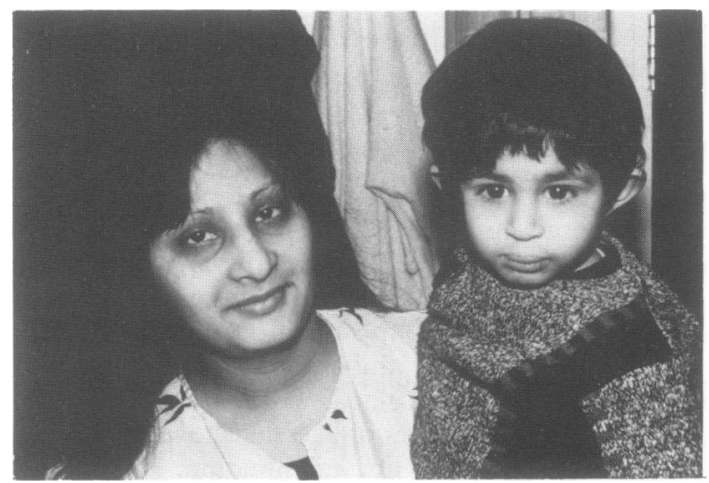

Figure 11 Mother and brother of case $4(I \cdot 1$ and II $\cdot 1$, family 2). Note short palpebral fissures. 


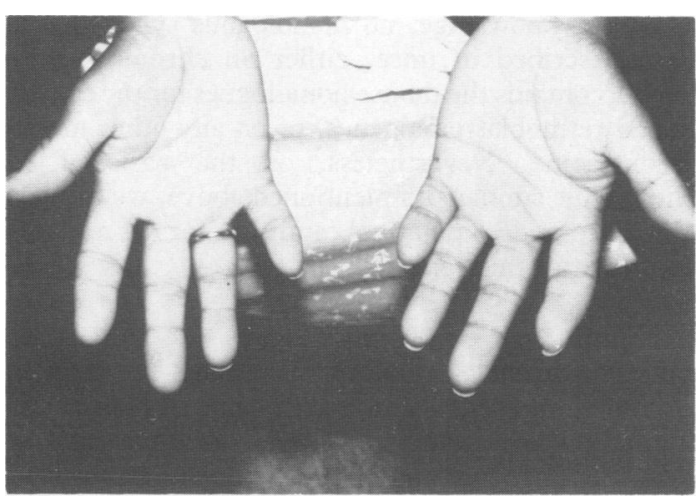

Figure 12 Mother of case $4(I \cdot 1$, family 2$)$. Note clinodactyly of the second and fifth fingers with single flexion crease on fifth finger.

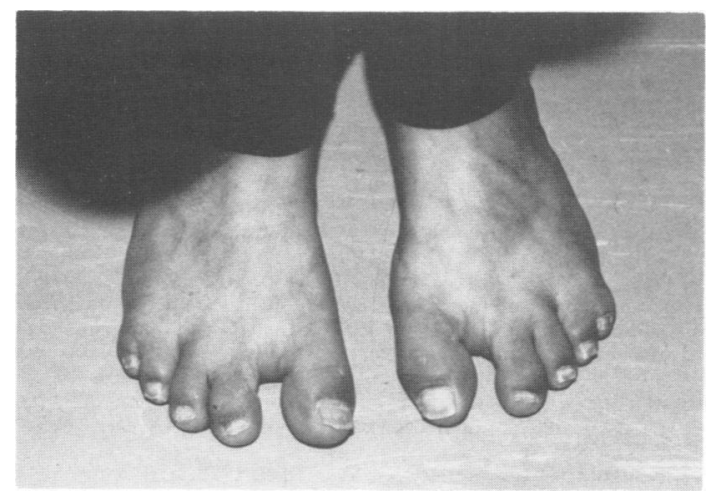

Figure 13 Feet of $I \cdot 1$. Note bilateral syndactyly $2 / 3$ and $4 / 5$ with wide space between toes 1 and 2 .

family 2 , intelligence appeared normal, but was not formally assessed.

INTESTINAL ABNORMALITIES

Four subjects in family 1 were born with oesophageal atresia. In two (III.8 and III.9) this was accompanied by a duodenal stenosis secondary to annular pancreas. III 4 was operated upon on the third day of life for duodenal atresia. The proband in family 2 (II $\cdot 2)$ also had congenital duodenal atresia.

\section{OTHER ABNORMALITIES}

One subject (III $\cdot 5$, family 1 ) has a unilateral total sensorineural deafness. Another (II $\cdot 5$, family 1$)$ has a missing upper lateral incisor tooth. The index case in family 1 (III $\cdot 8$ ) was born with tricuspid atresia, a $\mathrm{VSD}$, and an interrupted aortic arch.

\section{Discussion}

Feingold $^{78}$ briefly reported two families with autosomal dominant inheritance of microcephaly with normal intelligence and hand and foot abnormalities. In the first family described by this author, ${ }^{7}$ a boy, his father, and his paternal grandmother all had microcephaly and clinodactyly of the little fingers. Narrow palpebral fissures and syndactyly of toes $2 / 3$ were noted in the proband. In the initial report no mention is made of abnormalities of the feet in the other affected subjects, but a second report on this family ${ }^{8}$ mentions identical toe anomalies in both the father and the grandmother. The proband in the first family described by Feingold had a type $C$ tracheooesophageal fistula with concomitant duodenal atresia. Whether the internal manifestations were part of the syndrome was considered uncertain. The second family reported by Feingold consisted of a girl about whom no data are given, except for microcephaly and the presence of 'similar abnormalities' of the hands and feet. This constellation was also found in the mother. A maternal uncle and the maternal grandfather are reported as having exactly the same syndrome, all of them being of normal intelligence. ${ }^{8}$ No further details were provided. On the basis of the two families described here, the syndrome can now be more completely delineated. This syndrome shows apparently full penetrance and variable expressivity. Data are available on 21 subjects (nine males, 12 females) from four families. Transmission through

Clinical details of present families and those reported by Feingold. ${ }^{78}$

\begin{tabular}{|c|c|c|c|c|c|}
\hline & This & eport & Fein & $1 d^{78}$ & \\
\hline & $\begin{array}{c}\text { Family } 1 \\
(\mathrm{n}=11,4 M ; 7 \mathrm{~F})\end{array}$ & $\begin{array}{c}\text { Family } 2 \\
(\mathrm{n}=3,1 \mathrm{M} ; 2 \mathrm{~F})\end{array}$ & $\begin{array}{c}\text { Family } 1 \\
(\mathrm{n}=3,2 \mathrm{M} ; 1 \mathrm{~F})\end{array}$ & $\begin{array}{c}\text { Family } 2 \\
(n=4,2 M ; 2 F)\end{array}$ & $\begin{array}{c}\text { Total } \\
(\mathbf{n}=21,9 \mathrm{M} ; 12 \mathrm{~F})\end{array}$ \\
\hline Microcephaly & $4 / 8$ & $3 / 3$ & $3 / 3$ & $2 / 2$ & $12 / 16$ \\
\hline Short palpebral fissures & $7 / 8$ & $2 / 3$ & $1 / 1$ & $?$ & $10 / 12$ \\
\hline Clinodactyly 5 of hands & $11 / 11$ & $3 / 3$ & $3 / 3$ & $2 / 2$ & $19 / 19$ \\
\hline Syndactyly of toes & $11 / 11$ & $2 / 3$ & $3 / 3$ & $?$ & $16 / 17$ \\
\hline Intestinal atresia: & $5 / 11$ & $1 / 3$ & $1 / 3$ & $0 / 4$ & $7 / 21$ \\
\hline Oesophageal atresia/TOF & $4 / 11$ & $0 / 3$ & $1 / 3$ & $0 / 4$ & $5 / 21$ \\
\hline Duodenal atresia/stenosis & $3 / 11$ & $1 / 3$ & $1 / 3$ & $0 / 4$ & $5 / 21$ \\
\hline Congenital heart defect & $1 / 11$ & $0 / 3$ & $0 / 1$ & 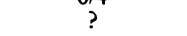 & $1 / 15$ \\
\hline
\end{tabular}


three generations in three families and male to male inheritance in the families described by Feingold ${ }^{78}$ suggest autosomal dominant inheritance.

The hallmark of the syndrome is the combination of clinodactyly of the fifth fingers bilaterally and syndactyly of the toes (usually 4/5). Head circumference is decreased compared to the normal sibs and about two-thirds of cases are microcephalic. In contrast to the reports by Feingold, ${ }^{78}$ we consider learning problems to be a frequent component of this syndrome. The most serious problem is the occurrence of oesophageal or duodenal atresia or both. Since three out of four families were ascertained through a proband with intestinal atresia, our estimate of its frequency $(33 \%)$ may be too high. However, after eliminating all probands, the frequency of intestinal atresias is still $4 / 17(24 \%)$. Case 1 had a severe congenital heart abnormality, which may be a low frequency feature of this syndrome.

Differential diagnosis includes disorders with syndactyly of the fourth and fifth toes, such as auralcephalosyndactyly ${ }^{9}$ and $13 q-$ syndrome, various forms of autosomal dominant microcephaly, ${ }^{10}$ and, finally, familial duodenal atresia ${ }^{11}$ and familial oesophageal atresia. ${ }^{4}$ However, the overall pattern of anomalies in the syndrome described here in combination with a normal chromosome analysis should allow easy recognition of this condition.

It is striking, that all features observed in the families reported here can also be found in patients with deletions of chromosome 13 distal to band 13q14. In patients with such deletions, hypoplastic thumbs, syndactyly of toes $4 / 5$, clinodactyly of the little fingers, and microcephaly with short palpebral fissures are all regularly observed. Oesophageal atresia and other intestinal atresias occur more rarely. ${ }^{12}$ However, G banded chromosomes were normal in cases 1,2 , and 4, while high resolution chromosome analysis in case 3 also failed to show any abnormality of chromosome 13 .
To our knowledge, no homologous syndrome has been described in mice, either on chromosome 14 (which contains the mouse homologues for the esterase $\mathrm{D}$ and retinoblastoma genes) or on any other murine chromosome. Nevertheless, on the basis of the phenotypic similarities mentioned above, we consider chromosome 13 a potential candidate for the mutation described in this report.

We wish to thank Drs Severijnen, van der Staak, Wilms, and Cuppen for providing additional clinical information on family 1 , and Dr Liberman for information on family 2 .

\section{Note added in proof}

Another mother and son with this syndrome have recently been described by König et al (Dysmorphol Clin Genet 1990;4:81-2).

1 David TJ, O'Callaghan SE. Oesophageal atresia in the south-west of England. 7 Med Genet 1975;12:1-11.

2 Szendrey T, Danyi G, Czeizel A. Etiological study on isolated esophageal atresia. Hum Genet 1985;70:51-8.

3 Chen H, Goei GS, Hertzler JH. Family studies on congenital esophageal atresia with or without tracheoesophageal fistula. Birth Defects 1979; 15(5C):117-44.

4 Van Staey M, de Bie S, Matton MT, De Roose J. Familial congenital esophageal atresia. Personal case report and review of the literature. Hum Genet 1984;66:260-6.

5 Warren J, Evans K, Carter CO. Offspring of patients with tracheo-oesophageal fistula. F Med Genet 1979;16:338-40.

6 Martinez-Frías ML, Frías JL, Salvador J. Clinical and epidemiological analysis of malformations. Am $\mathcal{F}$ Med Genet 1989;35: $121-5$.

7 Feingold M. Case report 30. Synd Ident 1975;3:16-7.

8 Feingold M. An unusual microcephaly. Hosp Pract 1978;13:44-9.

9 Kurczynski TW, Casperson SM. Auralcephalosyndactyly: a new hereditary craniosynostosis. F Med Genet 1988;25:491-3.

10 Opitz JM, Holt MC. Microcephaly: general considerations and aids to nosology. F Craniofac Genet Dev Biol 1990;10:175-204.

11 Best LG, Wiseman NE, Chudley AE. Familial duodenal atresia: a report of two families and review. Am $\mathcal{F}$ Med Genet 1989;34: 442-4.

12 Schinzel A. Catalogue of unbalanced chromosome aberrations in man. Berlin: De Gruyter, 1983. 